\title{
Restraint to the left ventricle alone is superior to standard restraint
}

\author{
Suyog A. Mokashi, MD, Lawrence S. Lee, MD, Jan D. Schmitto, MD, PhD, Ravi K. Ghanta, MD, \\ Siobhan McGurk, MS, Rita G. Laurence, BS, R. Morton Bolman III, MD, Lawrence H. Cohn, MD, and \\ Frederick Y. Chen, MD, PhD
}

\begin{abstract}
Objective: In standard ventricular restraint therapy, a single level of restraint is applied to the entire ventricular surface. We showed previously that at high restraint levels, cardiac tamponade develops because of the thinwalled right ventricle, even while the left ventricle remains unaffected. We now hypothesize that applying restraint exclusively to the left ventricle permits higher levels of restraint, resulting in increased benefit to the left ventricle.
\end{abstract}

\begin{abstract}
Methods: The acute effect of restraint applied to the left ventricle alone was analyzed in healthy and cardiomyopathic sheep hearts. Restraint therapy was applied by fluid-filled epicardial balloons placed solely around the left ventricle. Restraint level was defined by the measured balloon luminal pressure at end diastole. At incrementally higher restraint levels $(0,3,5,8,10,12$, and $14 \mathrm{~mm} \mathrm{Hg})$, transmural myocardial left ventricular pressure $\left(\mathrm{P}_{\mathrm{tm}}=\right.$ Left ventricle pressure - Balloon pressure $)$ and indices of myocardial oxygen consumption were measured in healthy sheep $(n=5)$ and in sheep with heart failure $(n=6)$.
\end{abstract}

Results: Increasing restraint from 0 to $14 \mathrm{~mm} \mathrm{Hg}$ decreased transmural myocardial pressure by $48.8 \%(P \leq .02)$ and the left ventricle tension-time index by $39.1 \%(P \leq .01)$, and the pressure-volume area decreased by $58.4 \%$ $(P \leq .01)$. Similarly, stroke work decreased by $57.9 \%(P \leq .03)$. Systemic hemodynamics were unchanged. There was no difference in the trend for all indices between animals that were healthy and those with heart failure.

Conclusions: We showed previously that, with standard restraint, right ventricle tamponade develops at high restraint levels, limiting restraint therapy. We now show that restraint applied to the left ventricle alone permits increased restraint levels, without causing right ventricle or left ventricle tamponade, for greater therapeutic benefit. We conclude that partial left ventricle restraint may be more effective than standard restraint. (J Thorac Cardiovasc Surg 2013;146:192-7)

Ventricular restraint therapy is a nontransplant surgical treatment for heart failure during which the entire ventricular surface is wrapped with a prosthetic material. ${ }^{1,2}$ The intent is to provide diastolic support to the failing heart and to prevent adverse ventricular remodeling. Current restraint devices have led to improvements in left ventricle (LV) volume, ejection fraction, and sphericity index, correlating with reverse remodeling. Currently, however, clinical restraint is applied in a manner that is neither measurable nor

From the Division of Cardiac Surgery, Brigham and Women's Hospital, Harvard Medical School, Boston, Mass.

This study was supported by the National Institutes of Health (Ruth L. Kirschstein National Research Service Award, F32HL095275-01A1, to Dr Mokashi; RO1HL090862, to Dr Chen); the Brigham and Women's Hospital, Cardiac Surgery Research Fund (to Dr Cohn, Dr Bolman); and a J. Paul Finnegan Cardiac Surgery Endowment (to Dr Chen).

Disclosures: Authors have nothing to disclose with regard to commercial support. The Brigham and Women's Hospital has patent rights on the device described in this article.

Received for publication Aug 16, 2012; revisions received Sept 4, 2012; accepted for publication Sept 13, 2012; available ahead of print Oct 18, 2012.

Address for reprints: Frederick Y. Chen, MD, PhD, Division of Cardiac Surgery, Brigham and Women's Hospital, 75 Francis St, Boston, MA 02115 (E-mail: fchen@ partners.org).

0022-5223/\$36.00

Copyright (C) 2013 by The American Association for Thoracic Surgery

http://dx.doi.org/10.1016/j.jtcvs.2012.09.027 adjustable, ${ }^{3-14}$ which may limit overall therapeutic efficacy. To address this, we previously developed an adjustable and measurable method of applying restraint using a fluid-filled, half-ellipsoidal balloon applied to the entire epicardial surface. ${ }^{15,16}$ We defined the restraint level as the balloon luminal pressure measured at end diastole. Using an ovine model of LV failure, a restraint level of 3 $\mathrm{mm} \mathrm{Hg}$ was found to be the optimal level that reduced myocardial wall stress acutely, and engendered reverse remodeling associated without causing associated cardiac tamponade. ${ }^{16} \mathrm{We}$ found that restraint levels of $5 \mathrm{~mm} \mathrm{Hg}$ or greater were associated with a significant increase in central venous pressure (CVP) and a reduction in mean arterial pressure (MAP), consistent with global tamponade physiology. ${ }^{16}$

Previously, it was unclear whether tamponade was secondary to impaired LV versus right ventricle (RV) filling. To address this question, our laboratory recently reported that ventricular restraint therapy affects the RV and LV quite differently. ${ }^{17}$ By increasing incrementally the restraint levels up to and beyond levels that cause tamponade, and by measuring separately the effects on each ventricle, we were able to analyze the effect of restraint on the LV versus the RV. We found that as restraint increased to higher levels, the LV continued to benefit, with improved transmural pressure and indices of myocardial oxygen consumption $\left(\mathrm{MvO}_{2}\right)$; 


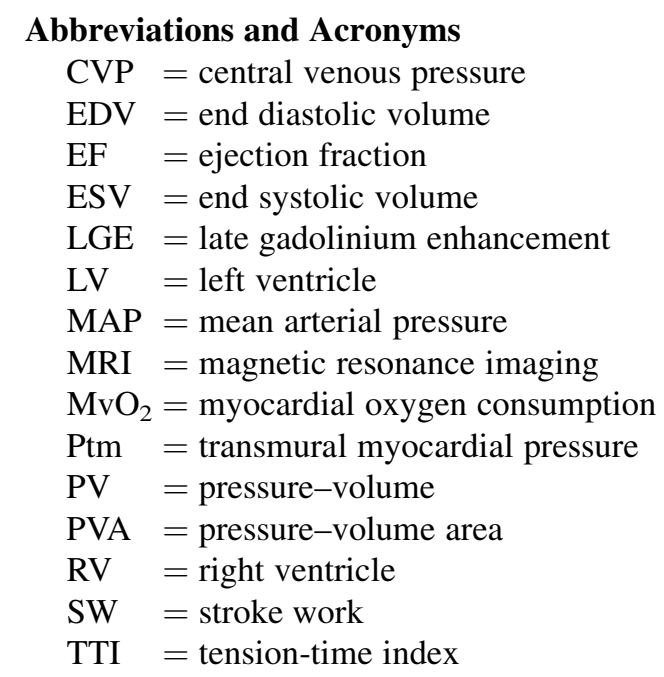

moreover, there were no adverse effect on LV diastolic compliance. ${ }^{17}$ The RV, however, behaved very differently. Even when restraint levels were increased, we found that RV transmural pressure remained unchanged whereas RV diastolic compliance decreased. ${ }^{17} \mathrm{We}$ concluded that the tamponade seen in standard restraint is caused by alterations that affect the RV only while the LV remains completely unaffected.

Because the high restraint levels adversely affect the RV only, is it possible to apply restraint to the LV alone and, if so, at much higher therapeutic levels than standard restraint without causing tamponade? We now hypothesize that restraint therapy can be applied solely to the LV with greater therapeutic efficacy than standard restraint, during which therapy is applied to both ventricles. We postulate that such a partial LV restraint permits higher levels of restraint without tamponade developing. In the experiments reported herein, healthy and cardiomyopathic sheep hearts were used to evaluate the immediate effects of partial $\mathrm{LV}$ restraint on systemic and ventricular parameters.

\section{METHODS}

\section{Study Overview}

All animals were cared for according to the standards set forth in the Guide for Care and Use of Laboratory Animals. ${ }^{18}$ published by the National Institutes of Health. The protocol was approved by the Institutional Animal Care and Use Committee at Harvard Medical School.

Eleven adult male sheep $(30-50 \mathrm{~kg})$ were used for this study, including healthy sheep $(n=5)$ and sheep with heart failure $(n=6)$. The immediate effects of partial LV restraint on systemic hemodynamics, transmural pressure, and indices of $\mathrm{MvO}_{2}$ were measured.

\section{Heart Failure Model}

Six animals underwent an initial surgery to create heart failure. Eight weeks after the first surgery, animals underwent cardiac magnetic resonance imaging (MRI; Figure 1). Heart failure was defined as LV ejection fraction $(\mathrm{EF}) \leq 40 \%$ and $\mathrm{a} \geq 100 \%$ increase in end diastolic volume (EDV) from baseline.
A postinfarction sheep model of heart failure was utilized. ${ }^{19}$ This model includes many of the features of human ischemic dilated cardiomyopathy and LV remodeling such as increased LV EDV and LV end-systolic volume (ESV), increased sphericity index, reduced LV EF, and decreased systolic wall thickening. Six cardiomyopathic sheep were used. A left anterior thoracotomy was performed through the fourth intercostal space. The diagonal branches of the left anterior descending coronary artery and obtuse marginal branches of the left circumflex coronary artery were identified. Magnesium ( $2 \mathrm{~g}$ intravenously), amiodarone $(1.5 \mathrm{mg} / \mathrm{kg}$ intravenously), and lidocaine ( $3 \mathrm{mg} / \mathrm{kg}$ intravenously) were given prior to infarction, along with an infusion of amiodarone $(0.01 \mathrm{mg} / \mathrm{kg} /$ minute $)$ and lidocaine ( $2 \mathrm{mg} /$ minute) for 60 minutes afterward. The distal aspects of multiple diagonal and obtuse marginal branches were ligated using 4-0 polypropylene sutures. The thoracotomy was closed in layers and the animals recovered. Postoperatively Buprenorphine $(5 \mu \mathrm{g} / \mathrm{kg}$ intramuscularly every 12 hours for 2 days) was given for pain control; cefazolin ( $4 \mathrm{mg} / \mathrm{kg}$ intramuscularly every 12 hours for 2 days) was given for antibiotic prophylaxis.

\section{Cardiac Magnetic Resonance}

Cardiac MRI was performed in the failure group at 8 weeks to confirm development of heart failure, as described previously. ${ }^{17}$ Animals were studied in a 3.0-T cardia magnetic resonance system (Signa CV/I; GE Healthcare, Waukesha, Wis) in the lateral decubitus position under general anesthesia and proper ventilation with an 8-element phased-array surface coil. A typical cardiac MRI study consisted of cine steady-state free precession imaging (repetition time, $3.4 \mathrm{msec}$; echo time, $1.2 \mathrm{msec}$; in-plane spatial resolution, $1.6 \times 2 \mathrm{~mm}$ ) of LV function and late gadolinium enhancement (LGE) imaging (repetition time, $4.8 \mathrm{msec}$; echo time, $1.3 \mathrm{msec}$; inversion time, 200-350 $\mathrm{msec}$ ) for myocardial scar. ${ }^{17}$ Peripheral pulse gating and breath holding were used as much as possible to minimize cardiac and respiratory motion, respectively. ${ }^{17}$ When breath holding was not achieved successfully, a free-breathing technique was applied using a multiple excitations-per-cycle approach associated with reduced views per segment. ${ }^{17}$ Cine imaging and LGE imaging were obtained in 8 to 14 matching short-axis ( $8 \mathrm{~mm}$ thick with 0 -mm spacing) and 3 radial long-axis planes. A previously described segmented inversionrecovery pulse sequence for LGE was used starting 10 minutes after administering the $0.2-\mathrm{mmol} / \mathrm{kg}$ dose of gadolinium DTPA. ${ }^{20,21}$

Cine function analysis was performed offline with validated software (QMASS 7.1; Medis Medical Imaging Systems, Inc, Leiden, The Netherlands). ${ }^{20,21}$ The cardiac phase that demonstrated the the smallest LV cavity size was defined as end systole; the largest LV cavity size was defined as end diastole. The endocardial contours of the RV and the LV were traced manually by the same experienced observer to determine the ventricular chamber volumes at end diastole and end systole. ${ }^{17}$ The papillary muscles were included in the ventricular cavity volume. Given that the basal slice contained both ventricular and atrial myocardium, the contours were drawn up to the junction of the atrium and the ventricle, and were joined by a straight line through the blood pool, as described previously. ${ }^{17}$ Left ventricle EF was computed using Simpson's rule: EF calculated as the difference between EDV and ESV as a percentage of EDV. ${ }^{17}$

LGE was interpreted as present or absent by the consensus of 2 cardiologists. Similar to our previous study, LGE was considered present only if myocardial enhancement was confirmed on both short-axis and matching long-axis locations. ${ }^{17}$ With a semiautomatic detection method, using a signal intensity threshold of $>3$ standard deviations above a remote reference region, the myocardial mass of LGE (measured in grams) was then quantified as previously reported. ${ }^{20,21}$

\section{Left Ventricular Adjustable and Measureable Ventricular Restraint}

The adjustable and measurable restraint device was described previously by our laboratory. ${ }^{16}$ Briefly, the device is a half-ellipsoidal balloon made of medical-grade polyurethane sheets (Polyzen, Inc, Apex, NC). Each balloon is comprised of 21 -mm-thick layers. The outer layer of the 


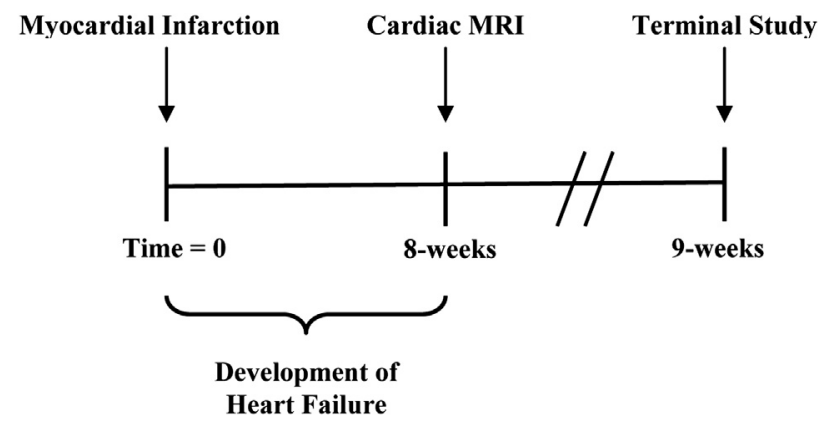

FIGURE 1. Timeline of heart failure creation and terminal study. Myocardial infarction is induced at time 0 ; cardiac magnetic resonance imaging $(M R I)$ to document heart failure is performed 8 weeks after myocardial infarction; and terminal study, 1 week after cardiac MRI.

balloon is a flexible but inelastic polyurethane layer whereas the inner layer is redundant. An access line is placed between the 2 layers to allow pressure measurement inside the balloon lumen and to permit the injection or withdrawal of fluid volume. Because the outer layer of the balloon is inelastic but flexible, fluid introduced into the balloon lumen has only 1 direction of filling space-inward toward the epicardial surface. Adjustment of luminal balloon fluid volume changes the restraint level applied. Restraint level is defined as the pressure measured at end diastole.

We modified the device such that the balloon would only encompass the LV epicardium to create the partial LV restraint device (Figure $2^{22}$ ). All devices were filled with saline solution and subjected to test pressures of 200 $\mathrm{mm} \mathrm{Hg}$ to ensure water tightness. Balloon luminal pressure was recorded in real time.

\section{Surgical Preparation and Instrumentation}

General anesthesia was induced by $6 \mathrm{mg} / \mathrm{kg}$ Telazol (Pfizer, New York, $\mathrm{NY}$ ) and $5 \%$ isoflurane, and maintained by $1 \%$ to $2 \%$ isoflurane. The left external jugular vein was cannulated with a pressure central venous catheter to measure CVP. Each animal was positioned supine and a median sternotomy was performed, followed by pericardiotomy. The inferior vena cava was dissected free and encircled with umbilical tape and snares. The aortic root was dissected and an electromagnetic aortic flow probe (Caroline Medical Electronics, King, NC) was placed around the aortic root to measure aortic flow. The right femoral artery was cannulated with a pressure transducer (Statham P10EZ transducer; SpectraMed, Oxford, Calif) catheter. A high-fidelity micromanometer catheter (Millar Instruments, Houston, Tex) was inserted in the RV through the ventricular wall, at the level of the outflow tract, and secured with purse-string sutures. Similarly, an $8 \mathrm{~F}$ conductance catheter (Webster Laboratories, Baldwin Park, Calif) and a micromanometer catheter were positioned longitudinally in the LV cavity through an apical purse-string suture. The conductance catheter consisted of 5 segments; 3 to 5 segments were used to measure ventricular volume. All electrocardiographic and hemodynamic signals were displayed for real-time analysis and were transferred to a minicomputer, where they were digitized at $200 \mathrm{~Hz}$ and stored for future analysis.

The partial LV restraint device was then positioned to envelop the LV completely. To secure this position, we sutured the anterior and posterior sewing skirts of the balloon, using 3-0 interrupted Ethibond sutures (Johnson and Johnson, Somerville, NJ), to the anterior and posterior RV epicardial wall. Next, the circumferential sewing skirt of the balloon was sutured along the atrioventricular groove, between the left atrium and ventricle, using 3-0 interrupted Ethibond sutures. Care was taken to avoid the coronary arteries (the anterior sewing skirt was secured to the RV $5 \mathrm{~mm}$ lateral to the left anterior descending artery; the posterior sewing skirt was secured to the $\mathrm{RV} 5 \mathrm{~mm}$ lateral to the posterior descending artery). The balloon access

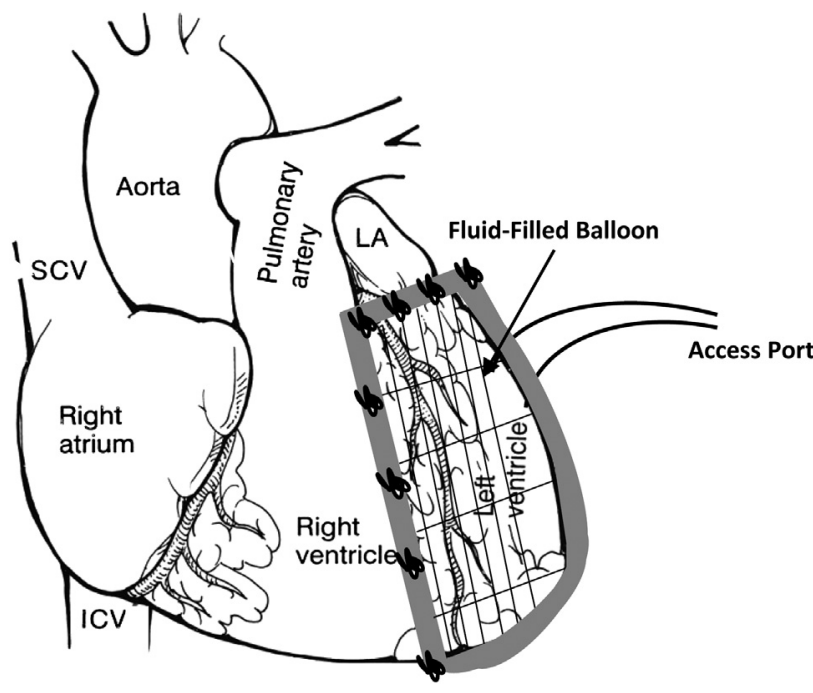

FIGURE 2. The partial left ventricular restraint device. A half-ellipsoidal fluid-filled balloon, which allows for adjustable and measurable restraint therapy, is positioned on the left ventricle. The restraint level may be adjusted by changing the volume of fluid instilled in the balloon. The anterior and posterior part of device are secured just right of the left anterior descending artery and posterior descending artery, respectively, whereas the superior part is secured to the heart along the atrioventricular groove. The outer layer is inelastic. $S C V$, Superior vena cava; $L A$, left atrium; $I C V$, inferior vena cava. (Modified from Cohn, ${ }^{22}$ Figure 2-2).

line was then connected to a Statham P10EZ pressure transducer to measure balloon pressure in real time.

\section{Data Collection}

Volume calibration episodes were performed to calculate the volume offset of the conductance catheter for a given data run. Twenty milliliters of $12.5 \% \mathrm{NaCl}$ was injected directly into the pulmonary artery via 21-guage needle to increase blood conductivity transiently while data were recorded for approximately 10 seconds.

For each subject, all signals were recorded at 7 incrementally increased ventricular restraint levels: 0, 3, 5, 8, 10, 12, and $14 \mathrm{~mm} \mathrm{Hg}$. Data were collected over 20 beats and with the ventilator off for 4 seconds to avoid respiratory variations. For preload reduction, required to obtain systolic and diastolic pressure-volume (PV) relations, umbilical tape encircling the inferior vena cava was tightened for approximately 10 seconds or until peak LV pressure fell by $50 \%$.

Individual restraint levels were defined by the maximum pressure applied by the balloon to the LV epicardium given a constant volume of fluid within the balloon lumen. To change restraint level, fluid was added or removed from the balloon while balloon pressure was monitored in real time. By measuring the luminal pressure within the balloon when the heart is largest in size (end diastole), wrap tightness was quantified precisely.

\section{Data Analysis}

Data analysis was performed on a microcomputer using the computational program MATLAB (The Mathworks, Natick, Mass).

Marking beats. The beginning of ejection was defined as the point where aortic flow first became non- 0 after end diastole. The end of ejection was identified by the point where aortic flow fell to 0 after the beginning of ejection. End diastole was defined as the point where LV pressure began to increase after diastole. End systole was defined at the same point as end ejection. Hemodynamic signals were ensemble averaged over 10 beats. 


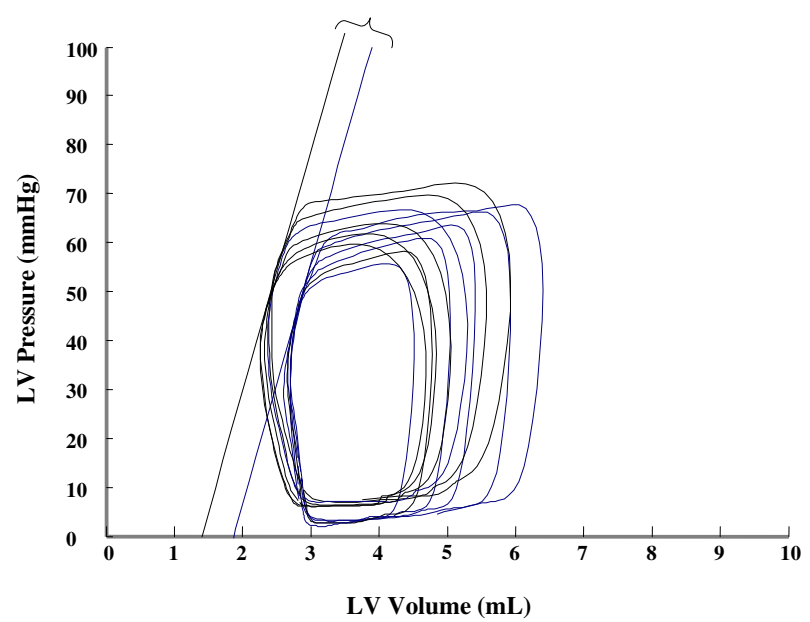

FIGURE 3. Immediate effect of partial restraint therapy on pressure-volume loops. The pressure-volume loop shifts toward the right with increased partial restraint therapy. $L V$, Left ventricle.

Volume calibration. Conductance catheter calibration parameters were calculated. The volume gain (1/a) was calculated from steady-state hemodynamic data using the aortic flow signal as a standard. The volume offset was calculated using the data from the hypertonic saline injections.

Steady-state data. Data were recorded at steady-state baseline conditions and during transient preload reduction. The steady-state data were calculated after averaging the first 5 steady-state beats of each episode. The following parameters were calculated: CVP, MAP, LV EDV, LV ESV, stroke volume, and LV pressure.

Transmural pressure. The transmural myocardial pressure $\left(\mathrm{P}_{\mathrm{tm}}\right)$ was measured throughout the cardiac cycle. By measuring balloon luminal pressure $\left(\mathrm{P}_{\mathrm{B}}\right), \mathrm{P}_{\mathrm{tm}}$ across the LV wall was defined as $\mathrm{P}_{\mathrm{tm}}=\mathrm{P}_{\mathrm{B}}-\mathrm{LV}$ pressure. Ventricular energetics. The pressure-volume area (PVA) and stroke work (SW) generated by the LV were calculated from a steadystate beat according the techniques described by Suga and associates. ${ }^{23}$ The PVA is the area between the end systolic PV relationship, end diastolic PV relationship, and the systolic portion of the PV loop, and it represents the total mechanical work generated by the LV. The SW, or external work, is the area within the PV loop; potential energy, or internal work, is the portion of the PVA that lies outside the PV loop. We also calculated transmural tension-time index (TTI), an index of $\mathrm{MvO}_{2}$, by integrating $\mathrm{P}_{\mathrm{tm}}$ with respect to time over the cardiac cycle.

\section{Statistical Analysis}

Mean values of parameters between groups were compared using a general linear mixed model. Repeated-measures data were assessed using a doubly multivariate repeated-measures design to control for the interrelatedness of our outcomes. Statistics were performed using SPSS 13.0 (IBM, Chicago, Ill). Results with a $P$ value $\leq .05$ were considered significant. All data are expressed as mean \pm standard error.

\section{RESULTS}

Incrementally higher levels of restraint were applied successfully to the LV epicardial surface alone. The following 7 restraint levels were tested: baseline $(0 \mathrm{~mm} \mathrm{Hg}), 3 \mathrm{~mm} \mathrm{Hg}$, $5 \mathrm{~mm} \mathrm{Hg}, 8 \mathrm{~mm} \mathrm{Hg}, 10 \mathrm{~mm} \mathrm{Hg}, 12 \mathrm{~mm} \mathrm{Hg}$, and $14 \mathrm{~mm} \mathrm{Hg}$. Typical PV loops with 2 separate restraint levels are shown in Figure 3.

\section{Systemic Hemodynamics}

Systemic hemodynamics remained unchanged. There were no significant changes from baseline in MAP and CVP, as illustrated in Figure 4.

\section{Indices of Left Ventricular Myocardial Oxygen Consumption}

Table 1 displays the effect of restraint levels on the following indices: $\mathrm{MvO}_{2}, \mathrm{LV} \mathrm{P}_{\mathrm{tm}}, \mathrm{LV}$ TTI, PVA, and SW. Each index was calculated for each restraint level. Left ventricle $\mathrm{P}_{\mathrm{tm}}$ decreased significantly, with the greatest decrease occurring at higher restraint levels. Compared with baseline, there was a significant $30 \%$ decline in $\mathrm{LV} \mathrm{P}_{\mathrm{tm}}(35.2$ $\pm 3.2 \mathrm{~mm} \mathrm{Hg}$ vs $23.0 \pm 0.6 \mathrm{~mm} \mathrm{Hg} ; P \leq .04$ ) at a restraint level of $10 \mathrm{~mm} \mathrm{Hg}$ and a $51 \%$ decrease at a restraint level of $14 \mathrm{~mm} \mathrm{Hg}(35.2 \pm 3.2 \mathrm{~mm} \mathrm{Hg}$ vs $18.0 \pm 1.1 \mathrm{~mm} \mathrm{Hg} ; P \leq$ .03). The decrease in $L V P_{t m}$ (a positive benefit) was greater with increasing restraint levels. The LV TTI also decreased significantly by $45 \%$ from baseline $(16.5 \pm 0.8$ vs $9.0 \pm$ $0.3 ; P \leq .01)$ at a restraint level of $14 \mathrm{~mm} \mathrm{Hg}$ (Table 1). Similar to the LV TTI, PVA and SW each continued to decrease with greater restraint applied (Table 1). When compared with baseline values, at a restraint level of $14 \mathrm{~mm} \mathrm{Hg}$, the
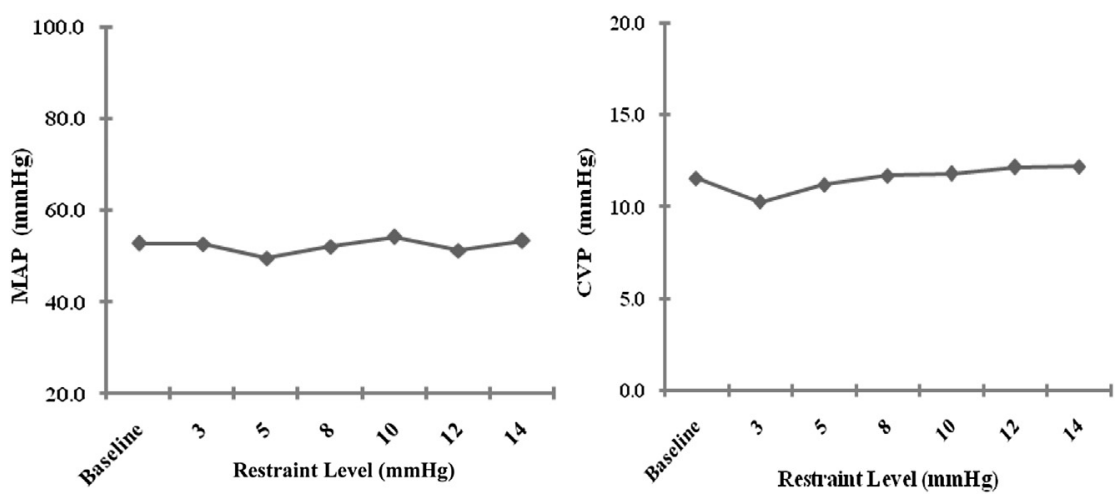

FIGURE 4. Mean aortic pressure $(M A P)$ and central venous pressure $(C V P)$ as a function of left ventricular restraint level. Despite increasing the restraint level upward of $12 \mathrm{~mm} \mathrm{Hg}$ and $14 \mathrm{~mm} \mathrm{Hg}$, the MAP and CVP remain unchanged. 
TABLE 1. Effect of restraint level on indices of myocardial oxygen consumption

\begin{tabular}{|c|c|c|c|c|}
\hline Restraint level, mm Hg* & $\begin{array}{c}\text { Transmural pressure, } \\
\text { mm Hg } \dagger\end{array}$ & $\begin{array}{c}\text { Tension-time index, } \\
\text { mm Hg/sec } \ddagger\end{array}$ & $\begin{array}{c}\text { Pressure-volume area, } \\
\mathrm{kg} / \mathrm{m}^{2} / \mathrm{sec}^{2} \S\end{array}$ & $\begin{array}{l}\text { Stroke work, } \\
\text { mm Hg/mL }\end{array}$ \\
\hline Baseline & $35.2 \pm 3.2$ & $16.5 \pm 0.8$ & $3642 \pm 459$ & $2601 \pm 679$ \\
\hline 3 & $31.8 \pm 1.4$ & $15.5 \pm 0.1$ & $3139 \pm 273$ & $1800 \pm 416$ \\
\hline 5 & $28.5 \pm 1.1$ & $14.0 \pm 0.3$ & $2661 \pm 279$ & $1559 \pm 304$ \\
\hline 8 & $25.6 \pm 1.2$ & $12.5 \pm 0.39$ & $2110 \pm 103$ & $1445 \pm 312$ \\
\hline 10 & $23.0 \pm 0.69$ & $11.3 \pm 0.29$ & $2230 \pm 242$ & $1252 \pm 340$ \\
\hline 12 & $20.5 \pm 0.99$ & $10.0 \pm 0.39$ & $1652 \pm 337^{*}$ & $1158 \pm 390^{*}$ \\
\hline 14 & $18.0 \pm 1.19$ & $9.0 \pm 0.39$ & $1515 \pm 433^{*}$ & $1096 \pm 451^{*}$ \\
\hline
\end{tabular}

Values expressed as mean \pm standard error. *Balloon pressure applied to left ventricle epicardial surface. $\dagger$ Balloon pressure less the left ventricle luminal pressure. $\ddagger$ Index of left ventricle myocardial oxygen consumption. $\S$ Total mechanical work generated by the left ventricle. $\|$ External work generated by the left ventricle. $₫ P$ value $\leq .05$ vs baseline.

PVA decreased significantly by $58 \%$ from $3642 \pm 459 \mathrm{~kg} /$ $\mathrm{m}^{2} / \mathrm{sec}^{2}$ to $1515 \pm 433 \mathrm{~kg} / \mathrm{m}^{2} / \mathrm{sec}^{2}(P \leq .01)$, and the SW also decreased significantly by $58 \%$ from $2601 \pm 679$ $\mathrm{mm} \mathrm{Hg} / \mathrm{mL}$ to $1096 \pm 451 \mathrm{~mm} \mathrm{Hg} / \mathrm{mL}(P \leq .03)$.

\section{Ventricular Luminal Pressure}

Figure 5 illustrates the effects of increasing LV restraint level on LV luminal pressure. The LV luminal pressure begins to increase significantly at the $10-\mathrm{mm} \mathrm{Hg}$ restraint level. Yet, as mentioned earlier, the CVP and MAP remain unchanged at the 14-mm Hg restraint level, and transmural pressure continued to decrease (Figure 5).

\section{DISCUSSION}

Previously, we developed a quantitative ventricular restraint device to apply ventricular restraint in an adjustable and measurable manner to both ventricles. ${ }^{16} \mathrm{~A}$ halfellipsoid, fluid-filled epicardial balloon is wrapped around the ventricular epicardial surface. The fluid within serves as the sole means of applying restraint therapy. ${ }^{23}$ With this technique, we found that $3 \mathrm{~mm} \mathrm{Hg}$ was the optimal restraint level at which the greatest reductions in $\mathrm{LV} \mathrm{P}_{\mathrm{tm}}$ and

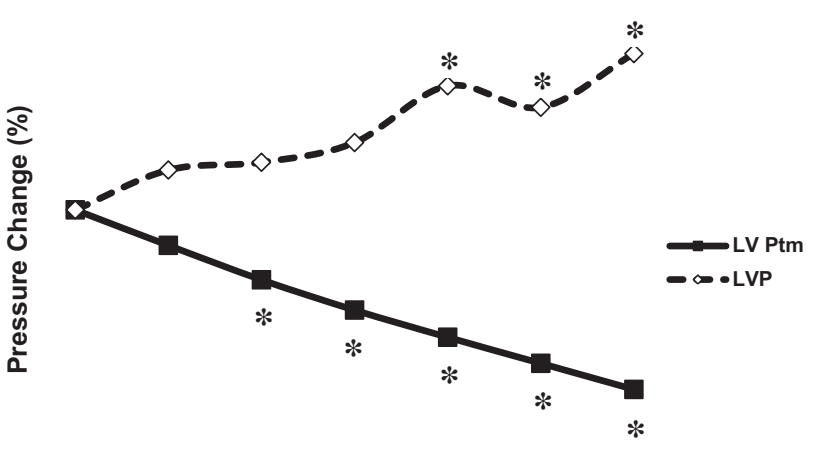

Restraint Level $(\mathrm{mmHg})$

FIGURE 5. Partial restraint therapy and left ventricular $(L V)$ luminal and transmural pressure. At the 5 to 8 -mm $\mathrm{Hg}$ restraint level, the LV luminal pressure begins increasing. The LV transmural pressure, however, continues to decrease significantly. ${ }^{*} P<.05$ for change from baseline. $P_{t m}$, Transmural myocardial pressure; LVP, left ventricular chamber pressure.
$\mathrm{MvO}_{2}$ indices occurred without alteration of systemic hemodynamics. ${ }^{16}$ At a restraint level of $5 \mathrm{~mm} \mathrm{Hg}$, however, frank cardiac tamponade developed, manifested by a decrease in MAP of $10 \mathrm{~mm} \mathrm{Hg}$ with increased CVP. Using an chronic ovine model of LV heart failure, we showed that applying $3 \mathrm{~mm} \mathrm{Hg}$ of restraint over a 2-month period led to reversal of adverse LV remodeling. ${ }^{16}$

Because it was not clear whether the tamponade that occurred at high restraint levels was secondary to impaired RV or LV filling, we studied the simultaneous effect of restraint on each ventricle. ${ }^{17} \mathrm{We}$ found that ventricular restraint therapy affects the RV and LV quite differently. Increasing the level of restraint led to additional decreases in $\mathrm{LV} \mathrm{P}_{\mathrm{tm}}$ whereas the LV diastolic compliance remained unchanged. ${ }^{17}$ Restraint therapy on the RV, however, had a very different effect. With greater restraint pressure, the RV $\mathrm{P}_{\mathrm{tm}}$ stayed the same, instead of decreasing, whereas $\mathrm{RV}$ diastolic compliance decreased significantly. ${ }^{17} \mathrm{By}$ increasing the level of restraint therapy, RV filling was impaired. ${ }^{17}$ We concluded that restraint therapy has little or no benefit on the RV, and indeed limits the overall therapeutic efficacy of ventricular restraint therapy.

In the current study, we modified our laboratory's quantitative ventricular restraint device for therapy on the LV only. The RV was excluded. We investigated the acute effect of partial LV restraint therapy on systemic and ventricular parameters in healthy sheep hearts and sheep hearts that experienced heart failure. Each parameter was measured and calculated as a function of restraint level, which was increased incrementally from 0 to 14 $\mathrm{mm}$ Hg. Variable loaded PV loops, which help avoid the potentially confounding effects of changes in loading conditions, were used to provide load-insensitive indices of ventricular function.

Increasing the restraint level resulted in marked decreases of $\mathrm{LV} \mathrm{MvO}_{2}$ indices-specifically, LV $\mathrm{P}_{\mathrm{tm}}$, TTI, PVA, and SW. Although the LV received these positive benefits, MAP and CVP were not altered, even at the higher levels of restraint applied.

With standard ventricular restraint, therapy could not be applied at a higher level $>3 \mathrm{~mm} \mathrm{Hg}$ without incurring 
tamponade. ${ }^{16}$ With partial LV restraint, much higher restraint levels could be applied safely to the LV. In our preliminary study, adverse systemic physiology did not develop despite a 14-mm $\mathrm{Hg}$ restraint pressure applied to the LV. This has the potential to lead to a much greater benefit of therapy than that measured in standard restraint. For example, in standard restraint, the safest maximum reduction in $\mathrm{LV} \mathrm{P}_{\mathrm{tm}}$ was $11.6 \%{ }^{16}$ With restraint to the $\mathrm{LV}$ alone, we found a reduction in $\mathrm{LV} \mathrm{P}_{\mathrm{tm}}$ of $52.4 \%$ at the highest restraint level tested of $14 \mathrm{~mm} \mathrm{Hg}$. The reduction in $\mathrm{LV} \mathrm{P}_{\mathrm{tm}}$ between partial and standard restraint, 52.4\% versus $11.6 \%$, was significant $(P<.001)$. Furthermore, with standard restraint, the LV TTI decreased from 16.8 $\mathrm{mm} \mathrm{Hg} / \mathrm{sec}$ at baseline to $14.5 \mathrm{~mm} \mathrm{Hg} / \mathrm{sec}$ with a restraint level of $3 \mathrm{~mm} \mathrm{Hg}$ (a reduction of $13.7 \%$ ). ${ }^{16}$ In the current study with partial LV restraint, the LV TTI was decreased safely from a baseline of $16.4 \mathrm{~mm} \mathrm{Hg} / \mathrm{sec}$ to $9.0 \mathrm{~mm} \mathrm{Hg}$ / $\mathrm{sec}$ at a $14-\mathrm{mm} \mathrm{Hg}$ restraint (a reduction of $45.1 \%$ ). Similarly, the reduction in LV TTI between partial and standard restraint, $45.1 \%$ versus $13.7 \%$, was also significant $(P<.001)$.

\section{Study Limitations}

The current study does have several limitations. First, this study measured the immediate effect of partial restraint therapy, not long-term results. Although an attractive hypothesis is that partial LV restraint would reverse adverse LV remodeling more than conventional restraint devices, that hypothesis remains to be tested and proved. Long-term experiments in a chronic LV failure model are necessary to investigate this hypothesis and, ultimately, clinical trials. A second limitation of this study is the maximum restraint level was never defined for partial LV restraint. A significant increase in CVP was not seen, nor was any significant decrease in systemic arterial pressure from baseline seen either, which leaves the possibility that even higher levels of restraint can be applied to the LV alone with even greater benefit than that reported here.

\section{CONCLUSIONS}

The current study substantiates the concept of partial LV restraint in which restraint therapy is applied to the LV alone. Our results suggest that partial LV restraint provides beneficial effects by decreasing transmural myocardial pressure, myocardial wall stress, and thus $\mathrm{MvO}_{2}$ in the acute setting. Furthermore, we documented more therapeutic benefit at higher restraint levels than that permitted by standard restraint devices. The use of partial LV restraint may provide a more effective therapeutic option for chronic LV heart failure than standard restraint therapy.

\section{References}

1. Oh JH, Badhwar V, Mott BD, Li CM, Chiu RC. The effects of prosthetic cardiac binding and a dynamic cardiomyoplasty in a model of dilated cardiomyopathy. J Thorac Cardiovasc Surg. 1998;116:148-53.

2. Converts WF, Shapland JE, Hotz H, Dushe S, Braun JP, Stantke K, et al. Passive containment and reverse remodeling by a novel textile cardiac support device. Circulation. 2001;104:1270-5.

3. Starling RC, Jessup M, Oh JK, Sabbah HN, Acker MA, Mann DL, et al. Sustained benefits of the CorCap cardiac support device on left ventricular remodeling: three year follow-up results from the Acorn clinical trial. Ann Thorac Surg. 2007;84:1236-42.

4. Mann DL, Acker MA, Jessup M, Sabbah HN, Starling RC, Kubo SH. Clinical evaluation of the CorCap cardiac support device in patients with dilated cardiomyopathy. Ann Thorac Surg. 2007;84:1226-35.

5. Acker MA. Clinical results with the Acorn cardiac restraint device with and without mitral valve surgery. Semin Thorac Cardiovasc Surg. 2005;17:361-3.

6. Magovern JA. Experimental and clinical studies with the Paracor cardiac restraint device. Semin Thorac Cardiovasc Surg. 2005;17:364-8.

7. Acker MA, Bolling S, Shemin R, Kirklin J, Oh JK, Mann DL, et al. Mitral valve surgery in heart failure: insights from the Acorn clinical trial. $J$ Thorac Cardiovasc Surg. 2006;132:568-77.

8. Oz MC, Konertz WF, Kleber FX, Mohr FW, Gummert JF, Ostermeyer J, et al. Global surgical experience with the Acorn cardiac support device. J Thorac Cardiovasc Surg. 2003;126:983-91.

9. Power JM, Raman J, Dornom A, Farish SJ, Burrell LM, Tonkin AM, et al. Passive ventricular constraint amends the course of heart failure: a study in an ovine model of dilated cardiomyopathy. Cardiovasc Res. 1999;44:549-55.

10. Pilla JJ, Blom AS, Brockman DJ, Ferrari VA, Yuan Q, Acker MA. Passive ventricular constraint to improve left ventricular function and mechanics in an ovine model of heart failure secondary to acute myocardial infarction. J Thorac Cardiovasc Surg. 2003;126:1467-76.

11. Cheng A, Nguyen TC, Malinowski M, Langer F, Liang D, Daughters GT, et al Passive ventricular constraint prevents transmural shear strain progression in left ventricle remodeling. Circulation. 2006;114:I79-86.

12. Saavedra WF, Tunin RS, Paolocci N, Mishima T, Suzuki G, Emala CW, et al. Reverse remodeling and enhanced adrenergic reserve from passive external support in experimental dilated heart failure. J Am Coll Cardiol. 2002;39:2069-76.

13. Sabbah HN. The cardiac support device and the myosplint: treating heart failure by targeting left ventricular size and shape. Ann Thorac Surg. 2003;75:S13-9.

14. Pina IL, Swain J. Corcap FDA panel presentation during the CDRH panel meeting. Washington, DC, 2005.

15. Rangaraj A, Umakanthan R, Lee LS, Laurence RG, Fox JA, et al. A new hear failure device: ventricular restraint decreases myocardial oxygen consumption indices. Presented at: the 42nd Annual Meeting of the Society of Thoracic Surgeons; January 30-February 1, 2006; Chicago, IL.

16. Ghanta RK, Rangaraj A, Umakanthan R, Lee L, Laurence RG, Fox JA, et al. Adjustable, physiological ventricular restraint improves left ventricular mechanics and reduces dilatation in an ovine model of chronic heart failure. Circulation. 2007; 115:1201-10.

17. Lee LS, Ghanta RK, Mokashi SA, Coelho-Filho O, Kwong RY, Bolman RM III et al. Ventricular restraint therapy for heart failure: the right ventricle is different from the left ventricle. J Thorac Cardiovasc Surg. 2010;139:1012-8.

18. National Institutes of Health. Guide for care and use of laboratory animals, revised. National Institutes of Health publication no. 85-23. Bethesda, MD National Institutes of Health; 1996.

19. Moainie SL, Gorman JH III, Guy TS, Bowen FW III, Jackson BM, Plappert T, et al. An ovine model of postinfarction dilated cardiomyopathy. Ann Thorac Surg. 2002;74:753-60.

20. Jauhiainen T, Jarvinen VM, Hekali PE, Poutanen VP, Penttila A, Kupari M. MR gradient echo volumetric analysis of human cardiac casts: focus on the right ventricle. J Comput Assist Tomogr. 1998;22:899-903.

21. Westenberg JJ, Lamb HJ, van der Geest RJ, Bleeker GB, Holman ER, Schalij MJ, et al. Assessment of left ventricular dyssynchrony in patients with conduction delay and idiopathic dilated cardiomyopathy: head-to-head comparison between tissue Doppler imaging and velocity-encoded magnetic resonance imaging. J Am Coll Cardiol. 2006;47:2042-8.

22. Cohn LH. Cardiac surgery in the adult. 3rd ed. New York, NY: McGraw-Hill; 2007.

23. Suga H. Ventricular energetics. Physiol Rev. 1990;70:247-77. 